that the atmosphere of London is far from being an astronomer's ideal, all the observations which led to the discoveries on which his fame rests were made in London. This great Cathedral seems the appropriate resting-place of a memorial to one whose life and work were so linked up with this city.

Sir William Huggins was a prominent example of a type of man to whom English science owes much, the non-official worker. Like his contemporaries, Darwin and Joule, he never held any professorship or scientific appointment. When in $185^{8}$ he retired from business at an unusually early age, he seems to have been undecided as to whether he should devote himself to the microscope or the telescope. The telescope gained the day, and he built an observatory at Tulse Hill; he began by making drawings of the planets, but seemed to be losing interest and to be rather despondent, when Kirchhoff's determination of the chemical elements in the sun by the aid of spectrum analysis came to his knowledge. This was to him, he said, like water in a thirsty land, and he determined to attempt to find out the constitution of the stars by the same method. At the beginning of I862 he persuaded Prof. Miller to join with him in the work, and in spite of the formidable difficulties 'due to the feebleness of the light, the mechanical difficulties of keeping the image of the star on the slit of the spectroscope, and the caprice of the London atmosphere, they were able to present to the Royal Society in $186_{3}$ a preliminary statement as to the spectra of some of the brighter stars; while in 1864 they published in the Philosophical Transactions of the Royal Society a general account of the spectra of about fifty stars, with a detailed study of some of the more important ones. They showed that the stars are made up of elements which, with few exceptions, are found in the earth. In 1864 Huggins made a discovery of capital importance in connection with the evolution of the stars, for he discovered a nebula the spectrum of which showed that it consisted of glowing gas, and was therefore in quite a different state of development from the stars he had examined, the spectra of which showed that their physical condition was analogous to that of the sun. Huggins threw himself with characteristic energy into the study of the spectra of the nebulæ, and found that the nebulæ were not all of one kind; some were stellar aggregates, while others were continuous masses of incandescent gases.

The importance of these results and the interest they excited were recognised by scientific societies with a promptitude almost without parallel. Three years after beginning serious scientific work he was elected a fellow of the Royal Society, the next year he was awarded a Royal medal, and after ten years he seems to have been elected to almost every scientific society in Europe. The work which commenced with such brilliance was carried on with undiminished ardour for nearly fifty years; since 1875 with the active co-operation of his wife. It showed throughout the characteristics so noticeable in the earlier work: the power to select the right problem to attack, the ability to devise the best way to attack it, and the industry to take boundless pains in overcoming the difficulties which sprang up at every turn.

On behalf of the Royal Society, I record with gratitude the help he gave to the work of that society, and especially to the distinction and dignity with which he for five years discharged the office of president. For the medallion we are indebted especially to $\mathrm{Mr}$. Pegram, the artist whose skill has produced it, and to Miss Montefiore, who has borne the burden of the heavy work necessary to bring such a scheme to completion.

NO. 2477, VOI. 99]

\section{THE DEVELOPMENT OF VEGETATION.'}

CONSIDERABLE scepticism is not infrequently expressed by botanists who are not ecologists as to the possibility of formulating a satisfactory natural classification of vegetation, i.e. of plant communities; and this scepticism is natural enough when we consider the numerous attempts, largely inconsistent and contradictory, that have been made in this direction, especially in recent years. It is obvious that the ultimate test of validity will be general acceptance, and certainly we cannot claim that there is anything like agreement among ecologists as to a natural scheme or as to the principles upon which such a scheme should be based. At the same time, it must be remembered that it took a very long time and constant efforts from many quarters to arrive at a natural system of classification of species which commanded anything like general acceptance. The task of the classifier of plant communities is much more difficult for many reasons, the chief of which is that the outlines of the classificatory units-the plant communities-are frequently vague and shifting, owing to the multiplicity of causes and combinations of causes which determine their nature and limits. Some would doubtless go so far as to say that the units themselves are illusory, but it is significant that this is not the view of those who have seriously studied vegetation in the field.

The natural system of species has been ultimately established on a phylogenetic-i.e. a developmental-basis, and any other was impossible once the principle of evolution had been accepted. Prof. Clements's fundamental contention in the volume under review is that the natural system of plant communities must also be established on a developmental basis, and he includes in his purview not only present vegetation, but all the past vegetations that have come into existence since plant-life first appeared on the earth. As the basis of this contention Prof. Clements claims that the plant formation-his basic unit-is an organism.

Whether that claim can be admitted or not depends, of course, upon our conception of an organism. Starting with individual animals and plants, which are the typical, or, as some might say, the only, organisms, it is clear that we can, if we so choose, extend the conception to human societies, for instance, which certainly have very many of the same characteristics, though they have not the close-knit spatial unity of structure and function of the individual plant or animal. If we extend the conception further to include plant formations in Clements's sense, we drop from our concept one of the characteristics of the higher animal organisms and of human communities-the conscious co-operation of parts in pursuit of the ends of the whole. But neither is this a character found in the lower animals or in plants. Unless, therefore, we definitely restrict our conception of organism to individual animals and plants, we must concede Clements's contention that plant formations are organisms, and if we do so restrict it we have perforce to admit that the plant formation has many of the characters of organisms, a fact which we may perhaps express by calling the vegetation unit a quasi-organism.

Prof. Clements's plant formation is the plant community in equilibrium with its climatic habitat, i.e. determined and kept constant by the control of a distinct climate. The type of such a formation is the forest of definite floristic composition which maintains itself indefinitely so long as the climate maintains its general character. Prof. Clements points out that such a community has a definite organisation, i.e. a fixed spatial and functional relation between the plants

1 "Plant Succession: an Analysis of the Development of Vegetation." "Prof. F. E. Clements. Pp. plates and 51 
composing it and with the substratum : it regenerates destroyed parts, and can reproduce itself in new situations; and, finally, it has a definite development or ontogeny.

It is this last feature with which the present volume is concerned. On bare ground or in water, within the climatic limits which determine the particular forest formation, there develops a succession of plant communities which ultimately gives rise to the forest. The causes of succession are the reactions of the successive plant populations on the habitat, which render it favourable to particular new invaders and less favourable to the existing occupants. The final stage, or climax, is reached when equilibrium is established and invasion no longer possible. The earlier course of development differs according to the nature of the substratum on which succession occurs, but the later phases correspond whatever the origin of the succession. This has been amply established in the case of several of the great forest climax formations of North America. As a particular instance W. S. Cooper has worked out in strikingly complete detail the successions culminating in the climax forest of Abies balsamea, Betula alba, var. papyrifera, and Picea canadensis on Isle Royale, Lake Superior. The primary successions in this case start from the bare rock shore or beach (xerarch successions), or from bogs and delta swamps (hydrarch successions), and through distinct series of definite and constant plant communities converge to the climax forest. Secondary successions are initiated by forest burns. If the humus is burned the resulting secondary succession is like the beach succession. When the humus is not burned the regeneration of the climax forest is much shorter.

In regions the climate of which does not permit of the establishment of forest the climax formations are of other vegetation types, such as desert or grassland; and here the successions from bare soil or water to the climax are shorter because woody plants are not involved.

Prof. Clements recognises the existence within the formation of associations which are "climax communities associated regionally to constitute the formation," and "are recognised chiefly by floristic differences." $\mathrm{He}$ thus maintains the practice almost universally agreed upon among ecologists of making the association a subordinate unit to the formation. Successively subordinate units of the association are designated as consociation (dominance of a single species), society, and clan. Parallel units are distinguished in the development series-i.e. those leading up to the formation in succession.

The author's foible is undoubtedly the multiplication of terms, a great number of which are proposed in this memoir. This is the concomitant of the compelling necessity he feels to establish complete systems of concepts logically worked out in every detail. Without entering upon a criticism of the validity of the conceptual systems themselves, which would occupy far more space than is at our disposal, it may be pointed out that the normal human mind invariably refuses to accept new concepts and terms until the progress of our knowledge of the relations of phenomena compels their adoption. It can scarcely be said that all Prof. Clements's terms are essential to clearness of thought and description. Some of them will no doubt come into general use, as some of the terms proposed in the author's "Research Methods in Ecology" (I905) have done.

The present work shows a great advance in maturity as the result of a wider experience, and is notable as the first systematic account of a fundamental phenomenon in vegetation. Its outstanding merit is logical thoroughness and completeness. It is impossible even to indicate the ground covered within the space of a short article.

The numerous photographs deserve quite special praise. They are not only of uniformly high standard and excellently reproduced, but they are admirably chosen to illustrate the text.

A. G. T.

\section{THE ZOOLOGY OF THE "TERRA NOVA" EXPEDITION.}

FOUR further reports on the zoological material collected during the British Antarctic (Terra Nova) Expedition, I9ro, have recently been issued by the British Museum (Natural History). Miss Massy (Zool., vol. ii., No. 7, pp. I4I-176, 43 figs.) describes sixty-eight specimens of Cephalopoda, which belong to seventeen species and twelve genera. Forty of the specimens belong to the Octopoda, the abundance of the genus Moschites being noteworthy.

The Decapod Crustacea, described by Mr. Borradaile (vol, iii., No. 2, pp. 75-110, 16 figs.), comprise forty-six species, but only three of these-all taken in the Ross Sea-are antarctic. In his account of Crangon antarcticus, Mr. Borradaile points out that the affinities of this antarctic shrimp lend some support to the hypothesis of bipolarity. One of the most interesting of the Decapods, a species of Porcellanopagurus taken off the northern end of New Zealand, forms the subject of a separate report (No. 3, pp. III-126, 13 figs.). Mr. Borradaile points out that Porcellanopagurus is one of the many attempts of Nature to evolve a crab. This crab seems to have been evolved from an ordinary hermit-crab, and the method followed was not only, as in other such cases, a broadening and depressing of the cephalothorax together with a reduction of the abdomen, but also a drawing out horizontally of the edges of the hard plate which roofs the fore part of the body of a hermit-crab. Mr. Borradaile traces the relations between the various external features of Porcellanopagurus and those of a hermit. crab. He surveys other routes by which evolution in the direction of "carcinisation" has proceeded throughout the Anomura, and reaches the conclusion that there is in the constitution of the Anomura a disposition or tendency to achieve that special formation of body which constitutes a crab. Whether the tendency be primarily one of morphology or of habits is another question, but, seeing that a similar form of body has been reached independently in circumstances which must have needed very different changes in the habits of the animals, it would appear that a morphogenetic tendency is the primary factor, but that it can only be realised in the event of the development of suitable habits. Mr. Borradaile remarks that there are few better instances than those afforded by "carcinisation" of the fact that the organism is, after all, the dominant factor in evolution.

In No. 4 (pp. 127-136, 7 figs.) Mr. Borradaile gives an account of the fourteen species of barnacles brought back by the expedition. The most interesting specimens described are some valves, referred to a new species of Hexelasma, collected in a glacier, $30 \mathrm{ft}$. above sea-level, in Evans Cove, Terra Nova Bay. It is not possible to state from their appearance whether these valves are recent or fossil, but it seems scarcely probable that they are recent, for no trace of such a barnacle has been found in any collection from either the Ross Sea or elsewhere, nor can any satisfactory suggestion be made as to the wav in which recent shells could have reached the position in which these were found. If they be fossil, it seems highly probable that they are, if not of Mincene age (their nearest known relation is $H$. aucklandicum 